\title{
Peroxiredoxin 6 is downregulated in platelets of first-onset psychosis
}

Helena PG Joaquim, Alana C Costa, Leda L Talib, Marcus V Zanetti, Wagner F Gattaz

\section{Introduction}

Markers of oxidative stress have already been considered a reflection of protective balance and degenerative mechanisms in psychoses. Peroxiredoxins (PRDXs) are among the key enzymes that belong to the antioxidant protection system. From these, the bifunctional enzyme PRDX6 has both activities associated with SCZ physiology: peroxidase and phospholipase A2 activity and, thus, has turned into an interesting target for studies.

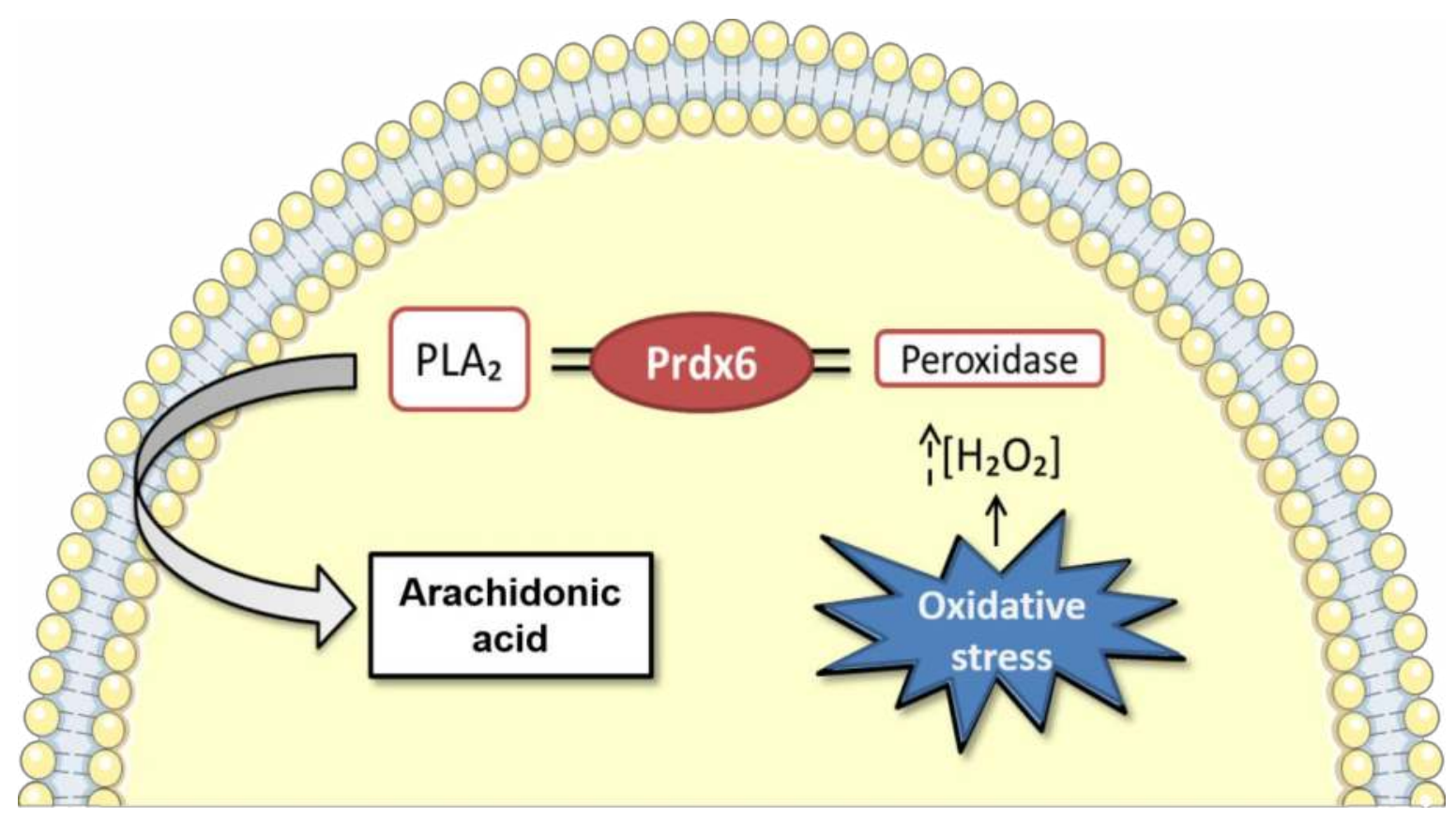

Figure 1. Both intracellular pathways for PRDX6 function

\section{Objective}

To determine the PRDX6 levels in first onset drug-naïve psychotic patients.

\section{Material and Methods}

Subjects

Table 1. Socio-demographic characteristics and clinical assessment

\begin{tabular}{lcccc}
\hline \multicolumn{1}{c}{ Diagnostic } & $\begin{array}{c}\text { Non-affective } \\
\text { Psychotic (n=28) }\end{array}$ & $\begin{array}{c}\text { Affective } \\
\text { Psychotic } \\
(\mathbf{n}=27)\end{array}$ & $\begin{array}{c}\text { Healthy } \\
\text { Control } \\
(\mathbf{n = 3 0})\end{array}$ & $\begin{array}{c}\mathbf{p} \\
\text { value }\end{array}$ \\
\hline Gender (M/F) & $17 / 11$ & $5 / 22$ & $16 / 14$ & 0.03 \\
\hline Age (mean \pm sd) & $26.0 \pm 7.4$ & $28.9 \pm 5.6$ & $26.2 \pm 3.9$ & 0.12 \\
\hline Years of education (mean \pm sd) & $10.8 \pm 3.5$ & $13.7 \pm 2.1$ & $14.7 \pm 2.3$ & 0.01 \\
\hline PANSS scores & & & & \\
\hline Total (mean \pm sd) & $78 \pm 22$ & - & - & \\
\hline Positive (mean \pm sd) & $19 \pm 5$ & - & - & \\
\hline Negative (mean \pm sd) & $18 \pm 8$ & - & - & \\
\hline HAM-D (mean \pm sd) & - & $15 \pm 8$ & - & \\
\hline YMRS (mean \pm sd) & - & $9 \pm 8$ & - & \\
\hline
\end{tabular}

$\mathrm{M}=$ male; $\mathrm{F}=$ female; $\mathrm{sd}=$ standard deviation; $\mathrm{AD}=$ Alzheimer Disease; $\mathrm{MCI}=$ Mild Cognitive impairment; MMSE=Mini-Mental State Examination; CAMCOG=Cambridge Cognitive Test; $p=$ significance of Chi-square test. M: male; F: female; sd: standard deviation; SCZ: Schizophrenia; BD: Bipolar disorder; PANSS: Positive and Negative Syndrome Scale (PANSS); HAM-D: Hamilton rating scale for depression; YMRS: Young Mania Rating Scale. Bold values indicate significant p-values.

\section{PRDX6 quantification}

After 8h fasting, blood samples of all subjects were collected in EDTA-coated tubes. The expression of PRDX6 was determined in platelets of patients and controls by western blotting (figure 2).

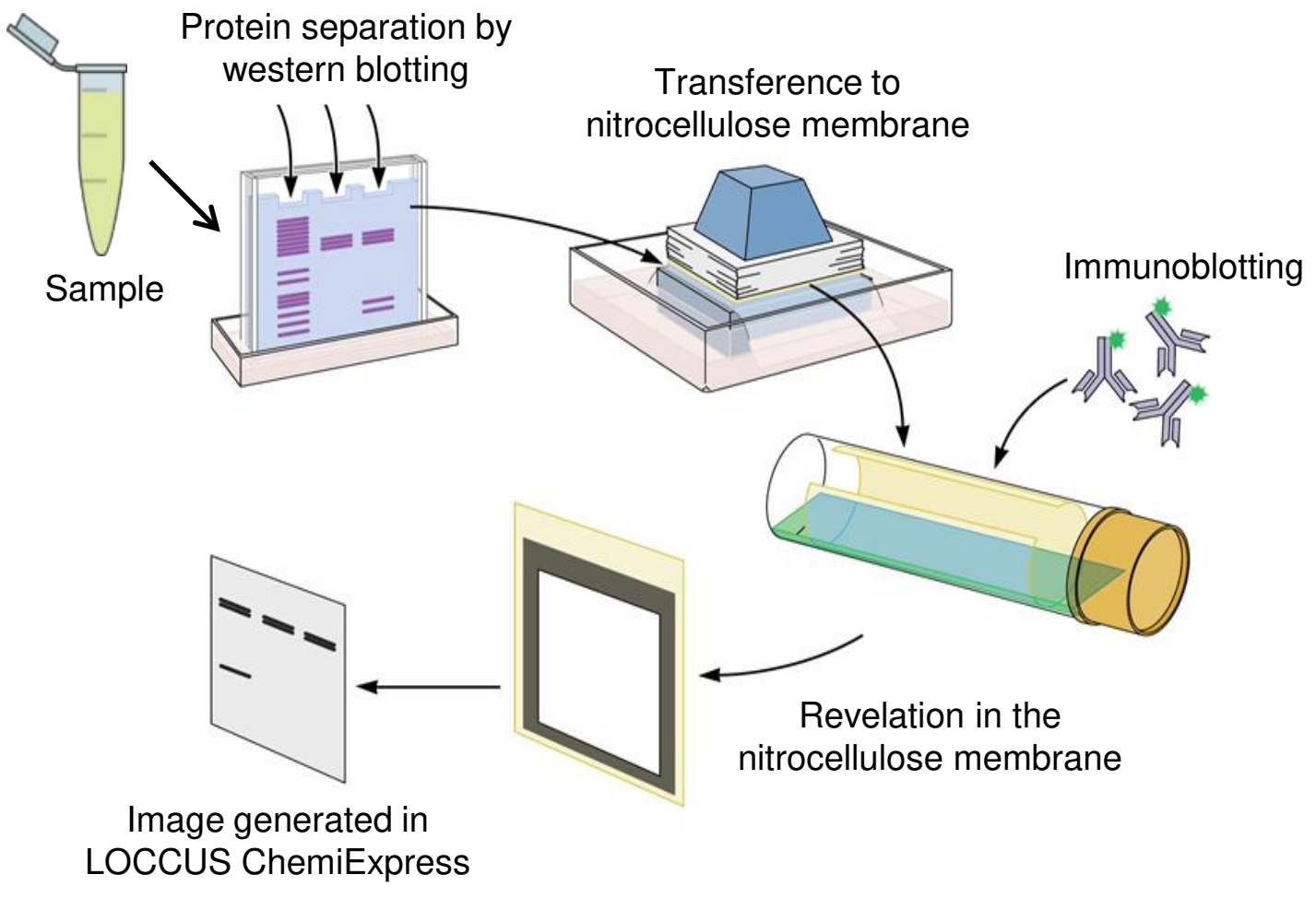

Figure 2. Western blotting procedure

\section{$\underline{\text { Results }}$}

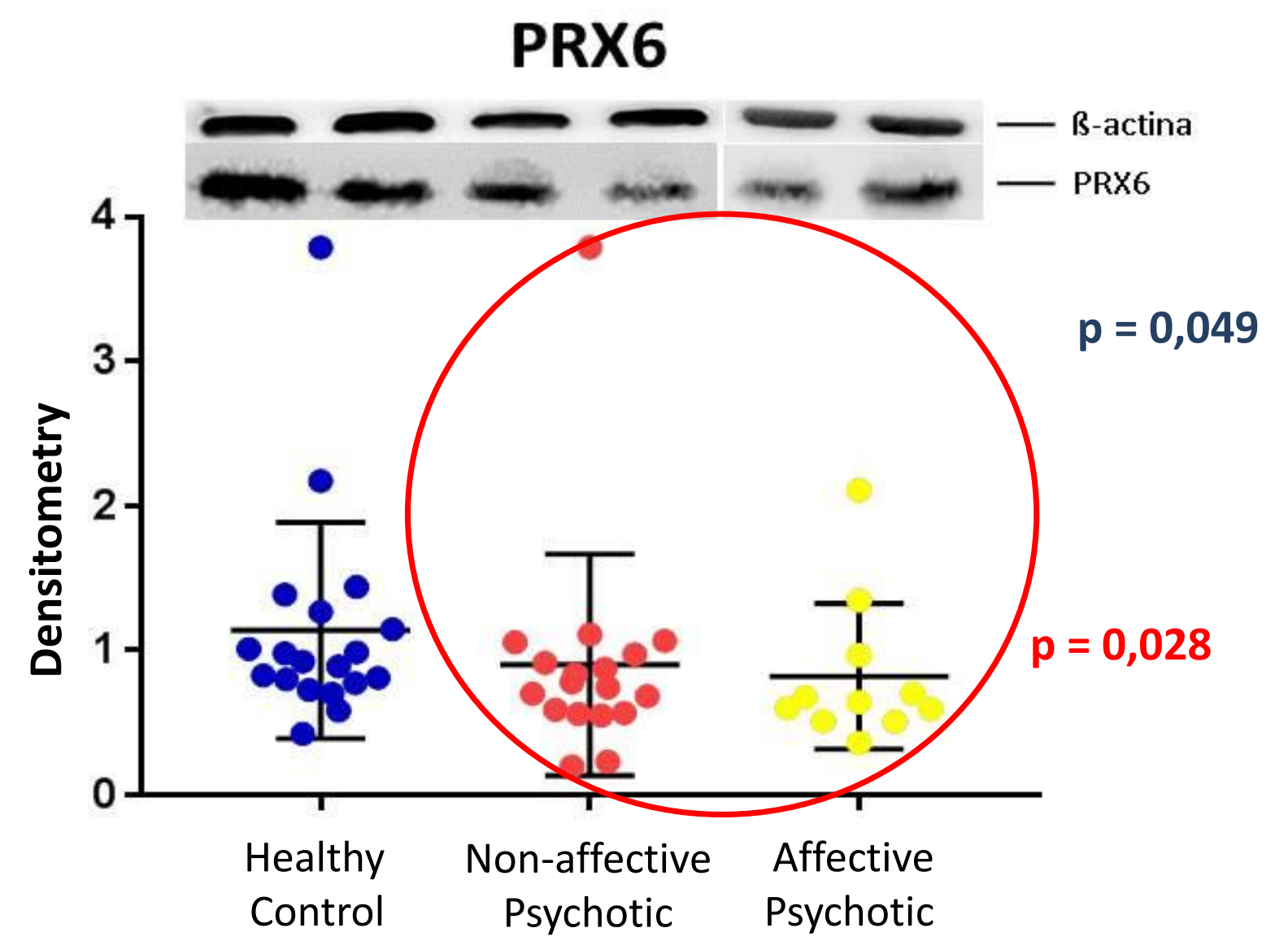

Diagnostic

\section{Conclusions}

- The role of PRDX6 in neuropsychiatry diseases may be controversial

- The binding of PRDX6 to different substrates regulates its peroxidase and IPLA2 activities

- In first onset psychosis antioxidant pathway is more prominent and informative in platelets 